\title{
Toros Göknarı (Abies cilicica Car.)'nda Yaprak Alan İndeksinin Belirlenmesi: Adana Kozan Yöresi Örneği
}

\author{
Determination of Leaf Area Index in Taurus Fir (Abies cilicica Car.): Case Study of Adana-Kozan
}

Ercan Oktan

Karadeniz Teknik Üniversitesi, Orman Fakültesi, Orman Mühendisliği Bölümü, Trabzon, Türkiye.

\section{Eser Bilgisi / Article Info}

Araştırma makalesi / Research article DOI: 10.17474/artvinofd.535526

Sorumlu yazar / Corresponding author

Ercan OKTAN

e-mail: oktan@ktu.edu.tr

Geliş tarihi / Received

04.03.2019

Düzeltme tarihi / Received in revised form

10.09.2019

Kabul Tarihi / Accepted

24.10.2019

Elektronik erişim / Online available

29.10.2019

\section{Anahtar kelimeler: \\ Abies cilicica \\ Yaprak Alan Indeksi \\ Silvikültür \\ Kapalılık \\ Verimlilik}

\section{Keywords:}

Abies cilicica

Leaf Area Index

Silviculture

Canopy closure

Productivity

\begin{abstract}
Özet
Yaprak alan indeksi (YAi), orman ekosistemlerinin temel yapısal karakterlerinin ortaya konmasında önemli araçların başında gelmektedir. Çünkü YAi meşcerenin tepe çatısında oluşan birçok biyolojik ve fiziksel sürecin değişimini ortaya koyabilmektedir. Bu bağlamda, YAi değerlerinin belirlenmesi ormancılık açısından önem taşımaktadır. YAi'nin hesaplanmasında doğrudan ve dolaylı birçok yöntem kullanılmaktadır. Bu çalışmada doğrudan belirlenme yöntemi kullanıımıştır. Bunun için farklı bakılarda, aynı yükseklik ve eğim ile yaklaşık aynı kapalıııkta (0.9-1.0) meşcerelerden toplam 45 adet ağaçtan alınan 180 sürgünde ölçümler yapılmıştır. Buna göre kuzey ve güney olarak farklı bakılardan alınan ağaçlarda yapılan YAi değerleri farkı (güney bakılardaki ağaçlarda $\bar{x}=1.892(\sigma=0.971$ ) ve kuzey bakılardaki ağaçlarda $\bar{x}=2.21$ ( $\sigma=0.93$ ) bulunmuştur. YAi değerleri kuzey bakıdan alınan örneklerde daha yüksek çıkmıştır. Bu sonuç, silvikültürel müdahalelerin yapılacağı meşcereler aynı meşcere yapısında olsa dahi farklı şiddette uygulamaların yapılması gerektiğini teyit etmektedir.
\end{abstract}

\begin{abstract}
Leaf area index is one of the most important factors in presenting the basic structural characteristics of forest ecosystems. Because, leaf area index can reveal the change of many biological and physical processes in the canopy. So, determination of the leaf area index is very important in forestry. In calculation of the leaf area index many direct and indirect methods are used. In this study direct method was used in calculation. For this purpose, measurements were made in 180 shoots taken from a total of 45 trees from different stands at the same altitude, aspect and have the same slope gradient and approximately same canopy closure (0.9-1.0). Obtained results showed that leaf area index was higher in the samples taken from North aspect $(\bar{x}=2.21(\sigma=0.93))$ then South $(\bar{x}=1.892(\sigma=0.971))$. Obtained results indicated that silvicultural treatments at different intensity should be carried out even if the stands were in the same stand structure.
\end{abstract}

\section{GiRiş}

Yaprak Alan Indeksi (YAi) ilk olarak Watson (1947) tarafından, birim yüzey alanı başına toplam tek taraflı yaprak dokusu alanı olarak tanımlanmıştır. Birçok araştırmacı bu tanıma dayanarak farklı vejetasyon türlerine göre tanımlamalar yapmışlardır. YAi için temel dayanak, bitkinin fotosentez yapan organları olan yapraklar olsa da zaman zaman dallar ve gövde de YAi hesaplamalarına dahil edilmiştir (Kucharik ve ark. 1998; Neves ve ark. 2013). Bazı araştırmalarda ise YAi birim toprak alanı üzerine düşen yaprak miktarı (Asner ve ark.2003) olarak tanımlarken Gower ve ark. (1999) tüm yaprakların alanı olarak tanımlamışlardır. Bunlara karşın Jonckheere ve ark. (2004), YAi'ni birim yüzey alanı başına düşen toplam yaprak alanının yarısı olarak tanımlanabileceği sonucuna varmışlardır. Birçok farklı tanımlama yapılıyor olmasına rağmen YAi'nin ana bileşeni bitkilerin yaşayan organları olan yaprak dokularının miktarlarının belirlenmesi tüm tanımlamaların ortak noktasını oluşturmaktadır.

Bu tanımlamalara göre, YAi bir ekosistemin tepe çatısını karakterize eden boyutsuz bir miktardır. YAi hem meşcere tepe çatısı içindeki hem de meşcere altındaki mikro iklimi harekete geçirir, meşcere tepe çatısı su alımını, radyasyon düzeyini, su ve karbon gazı değişimini belirler ve kontrol eder. Bu nedenle; ekosistemlerdeki biyojeokimyasal döngülerin kilit bir bileşenidir. Meşcerede don, fırtına, yaprak dökümü, kuraklık, silvikültürel müdahalelere bağıı 
olarak meydana gelen değişiklikler yaprak alan indeksini de değiştirir ve buna meşcere verimliliğindeki değişiklikler eşlik eder (Bréda, 2003). Bu nedenle; YAi meşcerenin verimliliğinin belirlenmesinde de kullanılmaktadır (Bonan, 1993; Clark ve ark. 2008; Liu ve ark. 2012; Jose ve Gillespie, 1997; Price ve Bausch, 1995; Waring, 1983). Meşcere verimliliğindeki değişimin YAi ile ortaya konabilmesi, meşcere yapısının tesis edilmesi aşamalarını içine alan bütün silvikültürel müdahalelerin şiddetinin belirlenmesine de yardımcı olabilecektir. Özellikle, silvikültürel müdahalelerle gerçekleştirilen, kapalıık değişimlerinin etkilerinin belirlenmesi açısından önemlidir.

Yaprak alan indeksinin belirlenmesi için birçok yöntem geliştirilmektedir. Bu yöntemler, doğrudan ve dolaylı ölçümler şeklinde ayrılmaktadır. Doğrudan ölçümler, alanda bulunan bitki vejetasyonun yaprak yüzey alanlarının ölçümü (Gower ve ark. 1999; Marshall ve Waring, 1986; Peper ve McPherson, 1998; Sumida ve ark. 2009) ve orman içi açıklıkların yaprak yüzey alanı ile ilişkisine dayandırılarak (Chen ve Black, 1992; Mason ve ark. 2012; Sampson ve Allen, 1995) yapılmaktadır. Dolaylı ölçümler ise, uydu görüntülerinden yararlanan uzaktan algılama yöntemleri (Hall ve ark. 2003; McAllister, 2005; Nagler ve ark. 2004; Yang ve ark. 2006) başta olmak üzere, kapalılık ve ışık analizleri yapan birçok optik cihaz (Behera ve ark. 2015; Chianucci ve ark. 2014; Kara ve ark. 2011) kullanılarak ya da sadece ağaçların çap değerleri (Turner ve ark. 2000) kullanılarak yapılmaktadır. Ancak, dolaylı yöntemlerin hepsi yersel ölçümlerin doğrulamasına ihtiyaç duymaktadırlar.

Bu çalışmada, saf Toros Göknarı meşcerelerinde YAI yersel ölçümlerle belirlenerek silvikültürel çalışmalarda kullanılabilme olanakları konusunda değerlendirmeler yapılmıştır.

\section{MATERYAL ve YÖNTEM}

\section{Materyal}

Çalışmada materyal olarak, Toros Göknarı'nın doğal yayılış alanlarından Adana Orman Bölge Müdürlüğü, Kozan Orman İşletme Müdürlüğü sınırları içerisinde yer alan saf meşcereler seçilmiştir (Şekil 1). Bu meşcerelerden, farklı bakılarda, aynı yükselti, aynı eğim ve yaklaşık aynı kapalılıkta (0.9-1.0) olanlar seçilmiştir. Seçilen meşcerelerden, 15 adet kuzey bakıda, 15 adet güney bakıda ve 15 adet rastgele bakılardan toplam 45 adet ağaçta ölçümler yapılmıştır.

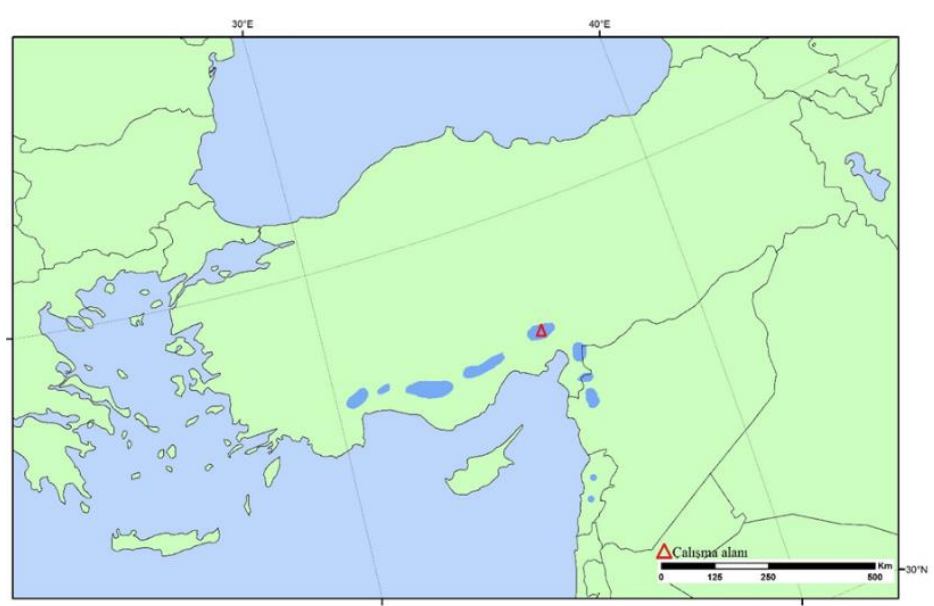

Şekil 1. Toros Göknarı'nın doğal yayılışı ve çalışma alanının coğrafi konumu

\section{Yöntem}

Çalışmada materyal olarak kullanılan 45 adet ağaç rastgele örnekleme (Bagnaresi ve ark. 2002; Magurran, 1988; 2004) yöntemine göre seçilmişlerdir. Seçilen ağaçların her birinin tepe çatısının orta noktasından ve 4 kardinal yönünden (Doğu-Batı-Kuzey-Güney) alınan 1'er metrelik toplam 180 sürgünde ölçümler yapılmıştır. Yapılan ölçümlerde kullanılan kriterler aşağıda çizelge 1 'de verilmiştir.

Çizelge 1: Ölçüm karnesi

\begin{tabular}{|c|c|c|c|c|c|c|c|c|c|}
\hline \multicolumn{3}{|c|}{$\begin{array}{l}\text { İ̧sletme Şefliği } \quad: \\
\text { Örnek Alan No } \quad: \\
\text { Ölçme Tarihi } \\
\text { Alan koordinatları: }\end{array}$} & & & & & & & \\
\hline \multirow{3}{*}{ Ağaç No } & & Örnek & & & & ürgü & & & \\
\hline & \multirow{2}{*}{ 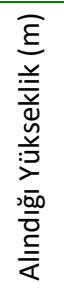 } & \multirow{2}{*}{ 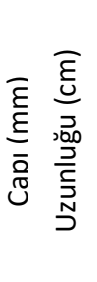 } & \multirow{2}{*}{ 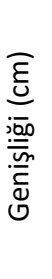 } & \multirow{2}{*}{$\begin{array}{l}\frac{\bar{d}}{\frac{0}{0}} \\
\frac{0}{0} \\
\frac{\bar{n}}{\sqrt{n}} \\
\text { ñ }\end{array}$} & \multirow{2}{*}{ 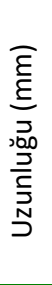 } & \multicolumn{2}{|c|}{$\begin{array}{l}\text { Genişliği } \\
(\mathrm{mm})\end{array}$} & \multirow{2}{*}{$\begin{array}{l}\bar{\xi} \\
\underline{\xi} \\
\bar{a} \\
\tilde{c}\end{array}$} & \multirow{2}{*}{$\begin{array}{c}\text { Genel } \\
\text { özellikler }\end{array}$} \\
\hline & & & & & & $\begin{array}{l}\text { d } \\
\text { సे } \\
\underline{y}\end{array}$ & 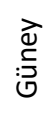 & & \\
\hline
\end{tabular}

Elde edilen verilerden, Peper ve McPherson (1998) tarafından kullanılan YAi hesaplama yöntemine 
dayanılarak uyarlanan aşağıdaki formülle çalışma alanı için YAi değerleri hesaplanmıştır.

$$
Y A \dot{\mathrm{I}}=\frac{\sqrt{\sum_{1}^{n} x_{1}^{2}+x_{2}^{2}+{ }_{\tan }^{2} B i}}{A}
$$

Formülde; YAi: Yaparak alan indeksi değeri, n: sürgün sayısı, X1: Kuzey yöndeki ibre uzunluğu, X2: Güney yöndeki ibre uzunluğu, B: Sürgün genişliği, A: Sürgün uzunluğu.

YAi hesaplamalarında, her ağaçtan alınan 1'er metre uzunluğundaki toplam 4 sürgün üzerindeki ibre büyüklükleri, sürgün üzerinde bulundukları yere göre ayrı ayrı ölçülerek yukarıdaki formülde yerine konularak sonuçlar elde edilmiştir. Böylelikle hem farklı bakılardaki ağaçlar için YAi değerleri hesaplanmış hem de her ağacın farklı yönlerindeki sürgünler için YAi değeri hesaplanmıştır. Bu sayede, farklı bakılardaki ağaçlar arasında YAi değeri açısından bir farkın olup olmadığı

ortaya konurken, aynı ağaç üzerindeki farklı yönlerdeki sürgünler açısından YAi değerinin değişip değişmediği ortaya konmaya çalışıımıştır. Hesaplanan YAi değerlerinin ağaçlar düzeyinde ve ağaç üzerinden alınan sürgünün alındığı yere göre farklılık gösterip göstermediği karar ağacı analizi (Baizyldayeva ve ark. 2013; Song ve Lu, 2015) ile test edilmiştir. Buna göre, aynı ve farklı kümelerde bulunan YAi oranlarının farklılıklarına göre silvikültürel değerlendirmeler yapılmıştır.

\section{BULGULAR}

Çalışmada, 45 adet ağaçtan elde edilen 180 sürgünde 2612 tane YAi değeri hesaplanmıştır. Tüm çalışma materyali için hesaplanan YAi değerleri 0.62 ile 13.15 $(\bar{x}=2.063, \sigma=1.17)$ aralığında değişmektedir. Tüm ağaçların YAi değerlerine göre oluşturulan karar ağacı aşağıda şekil 2'de verilmiştir.

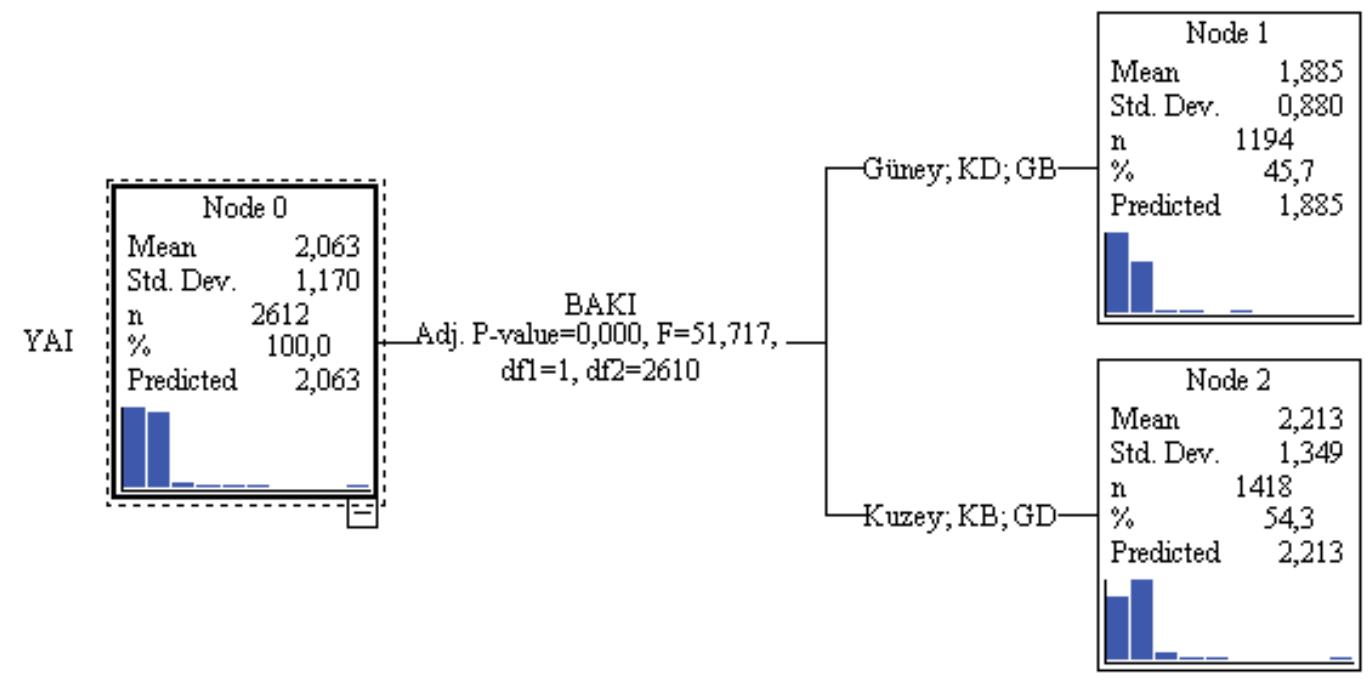

Şekil 2. Tüm ağaçların YAi değerlerine göre oluşan karar ağacı diyagramı.

Tüm ağaçlar dikkate alınarak oluşturulan karar ağacı diyagramı incelendiğinde, ilk grubun Güney, Kuzeydoğu ve Güneybatı, ikinci grubun Kuzey, Kuzeybatı ve Güneydoğu şeklinde oluştuğu görülmektedir. İlk grubun YAi değerleri ortalaması $\bar{x}=1.885(\sigma=0.88)$ olurken, ikinci grubun YAi değerleri ortalaması $\bar{x}=2.213(\sigma=1.349)$ olmuştur. Çalışmada, sadece kuzey ve güney bakılardaki 30 ağaçtan elde edilen 1836 tane YAi değerleri ise 0.62 ile $7.97(\bar{x}=2.05, \sigma=0.964)$ aralığında değişmektedir. Bu ağaçların YAi değerlerine göre oluşturulan karar ağacı aşağıda şekil 3 'de verilmiştir.
Çalışmada, sadece kuzey ve güney bakıdan örneklenen 30 ağaç dikkate alınarak oluşturulan karar ağacı diyagramı incelendiğinde, Güney bakıda bulunan ağaçların YAI değerleri ortalaması $\bar{X}=1.892(\sigma=0.971$ ) olurken, Kuzey bakıda bulunan ağaçların YAi değerleri ortalaması $\bar{x}=2.21$ $(\sigma=0.93)$ olmuştur.

Çalışmada, kuzey ve güney bakılardaki ağaçların her birinin 4 kardinal yönünden alınan sürgünlerin ayrı ayrı YAi değerlerini dikkate alarak oluşturulan karar ağacı aşağıda şekil 4'de verilmiştir. Diyagram incelendiğinde, güney bakıda bulunan ağaçlardan alınan sürgünlerin YAi 
değerlerinin iki grupta toplandığı görülmektedir. Bu gruplardan ilkinde, doğu, batı ve güney yönden alınan sürgünlerin toplandığı ve YAi değerleri ortalamalarının $\bar{x}=1.827$ ( $\sigma=0.631$ ) olduğu, ikinci grupta ise kuzey yönden alınan sürgünlerin toplandığı ve YAi değerleri ortalamalarını $\bar{x}=2.096$ ( $\sigma=1.611$ ) olduğu ortaya çıkmıştır. Diyagramda, kuzey bakıda bulunan ağaçlardan alınan sürgünlerin de YAi değerlerinin iki grupta toplandığı görülmektedir. Bu gruplardan ilkinde, batı ve kuzey yönden alınan sürgünlerin toplandığı ve $\mathrm{YAI}$ değerleri ortalamalarının $\bar{x}=2.43(\sigma=1.225)$ olduğu, ikinci grupta ise doğu ve güney yönden alınan sürgünlerin toplandığı ve YAi değerleri ortalamalarının $\bar{x}=2.012$ ( $\sigma=$ 0.462) olduğu belirlenmiştir.

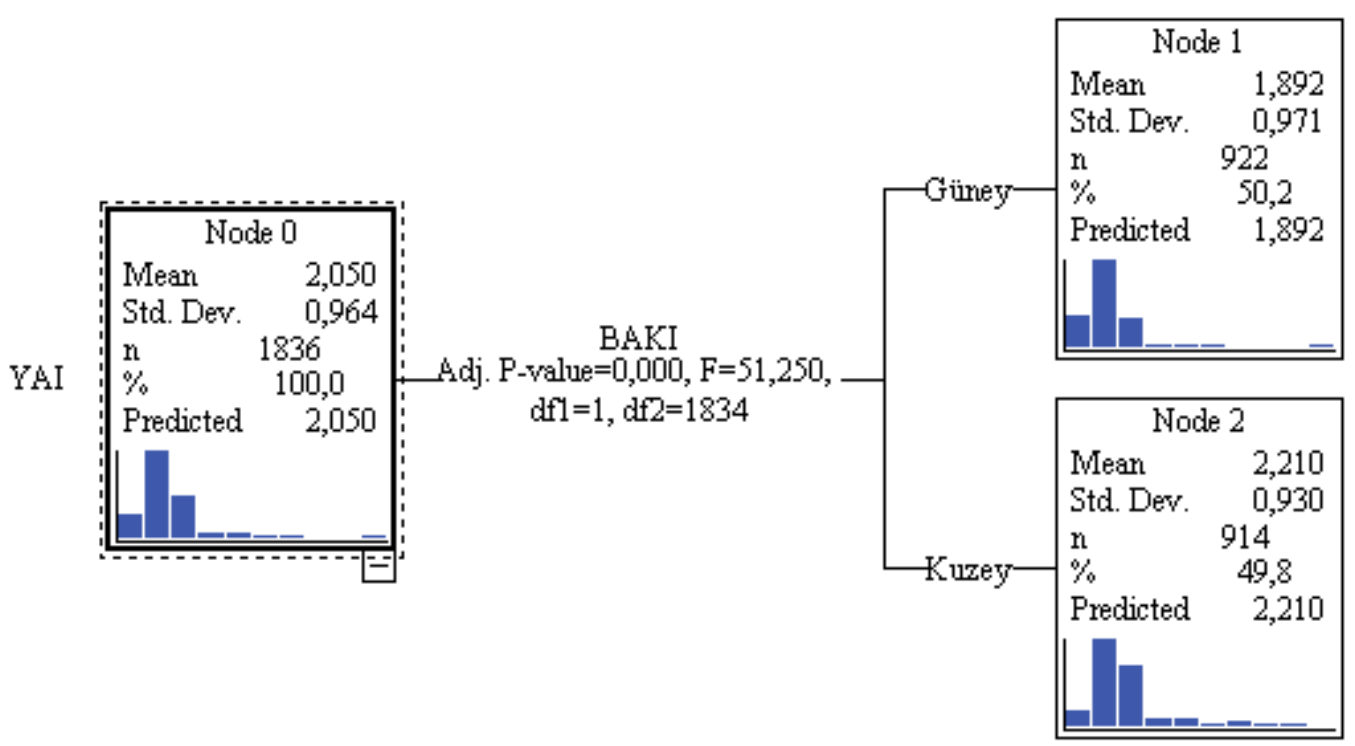

Şekil 3. 30 örnek ağacın YAi değerlerine göre oluşan karar ağacı diyagramı.

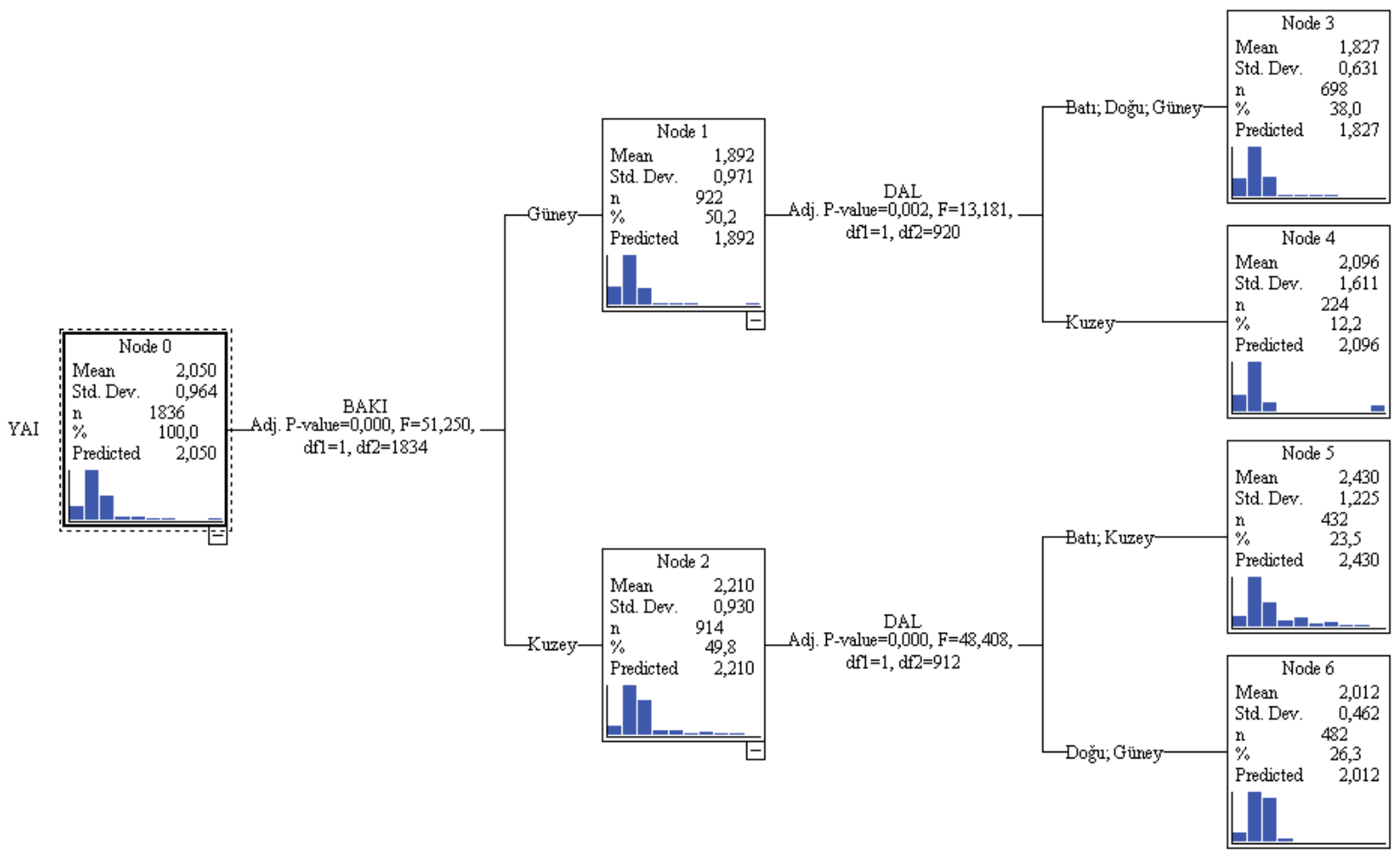

Şekil 4. 30 örnek ağacın 4 kardinal noktasından alınan sürgünlerin YAi değerlerine göre oluşan karar ağacı diyagramı 


\section{TARTIŞMA VE SONUÇ}

YAi hesaplamaları uzaktan algılama yöntemleriyle yapıldığında karşılaşılan en önemli sorun yersel ölçümlerle doğrulama gerektirmesidir. Diğer taraftan amaca uygun YAi değerlerinin ortaya konması da büyük önem taşımaktadır. Nitekim kimi zaman sadece meşcere kapalıı̆ı̆ını değerlendirilmesi için YAi'ne intiyaç duyulurken kimi zaman da toplam karbon stoku hakkında bilgi sahibi olabilmek için kullanılmaktadır. Her durumda uzaktan algılama yöntemleriyle tahmini değerler elde edildiği göz önüne alındığında, yersel ve nitelikli ölçümlerin yerini tutamayacağı açıktır (Bréda, 2003). Diğer taraftan uzaktan algılama yöntemleri ya da optik cihazlar kullanılarak yapılan tahminler yüksek kapalıık derecelerinde daha iyi sonuçlar vermekteyken, kapalılı̆ı̆n düşük olduğu orman alanlarında elde edilen sonuçlar tatmin edici değildir (Law ve ark. 2001; Van Pelt ve ark. 2016). Bu nedenle, YAi hesaplamalarının hangi amaç için yapılacağı önceden belirlenerek ölçme yöntemine karar verilmelidir.

Çalışmada, ayrıntılı yersel ölçümlerin yapılmasının temel amacı, Toros Göknarı meşcerelerinde uygulanacak silvikültürel müdahalelerin bakılar göre nasıl değişeceğinin ortaya konması olarak değerlendirildiğinde, mutlaka yersel ölçüm yapılması gerektiği ortaya çıkmaktadır. Nitekim elde edilen bulgular incelendiğinde, ağaçların bulundukları bakılara göre hatta ağacın kendi içindeki bakıya göre YAi'de farklılıklar olduğu açıktır (Bknz. Şekil 4). Bu bağlamda değerlendirildiğinde, kuzey, güney ve rastgele bakılardan alınan örneklerin tamamın YAI değerlerinin, kesin bir ayrım olmamasına rağmen, farklı gruplar oluşturduğu (Bknz. Şekil 2) görülmektedir. Diğer taraftan, sadece kuzey ve güney bakılardan alınan ağaçların YAi değerleri incelendiğinde, iki farklı grubun oluştuğu ve kuzey bakıdaki ağaçların daha yüksek YAi değerlerine sahip olduğu ortaya çıkmaktadır. Bu durum kuzey bakıdaki ağaçların daha yoğun yaprak alanına sahip olduğunu ifade etmektedir. Başka bir deyişle daha yoğun siper (ya da gölgeleme) yaptıklarını ortaya koymaktadır. Nitekim daha yüksek YAi değerine sahip alanların daha verimli olduğuna dair birçok araştırma sonucu (Clark ve ark. 2008; Jose ve Gillespie, 1997; Kara ve ark. 2011) bulunmaktadır. Öte yandan, kuzey ve güney yöndeki ağaçların kendi içlerinde sürgünlerin alındığı yöne göre farklııkların oluşması (Bknz. Şekil 4), meşcerenin bakısının yanında meşcere içinde yönlerin de dikkate alınması gerektiğini ortaya koymaktadır.

Yukarıda ortaya konan sonuçlar doğrultusunda değerlendirildiğinde, uygulanacak olan silvikültürel müdahalelerin (özellikle bakım müdahalelerinin) meşcerenin bakısı dikkate alınarak yapılmasının uygun olacağı değerlendirilmiştir. Öte yandan, aynı ağaç türü için ön görülecek silvikültürel müdahale sonrası kapalılık derecelerinin meşcere bakısına göre farklılık gösterebileceği hususunun göz ardı edilmemesi ortaya çıkmaktadır. Bu bağlamda, güney bakılarda ya da güneşli bakılarda, silvikültürel müdahalelerin daha mutedil yapılmasının daha iyi sonuçlar verebileceği unutulmamalıdır.

Yukarıda yapılan değerlendirmeler dikkate alındığında, diğer ağaç türlerimizin $\mathrm{YAI}$ değerlerinde, bu gibi farklııkların olup olmadığının ortaya konabilmesi için, benzer ya da daha ayrıntılı çalışmaların yapılması önerilebilir.

\section{KAYNAKLAR}

Asner GP, Scurlock JMO, Hicke JA (2003) Global synthesis of leaf area index observations: implications for ecological and remote sensing studies. Global Ecol. Biogeogr., 12;191-205.

Bagnaresi U, Giannini R, Grassi G, Minotta G, Paffetti D, Pini Prato E, Proietti Placidi AM (2002) Stand Structure and Biodiversity in Mixed, Uneven-aged Coniferous Forests in the Eastern Alps, Forestry, 75, 356-364.

Baizyldayeva UB, Uskenbayeva RK, Amanzholova ST (2013) Decision Making Procedure: Applications of IBM SPSS Cluster Analysis and Decision Tree. World Applied Sciences Journal 21 (8), pp. 12071212.

Behera SK, Behera, MD, Tuli R (2015) An indirect method of estimating leaf area index in a tropical deciduous forest of India. Ecological Indicators 58, pp. 356-364.

Bonan GB (1993) Importance of leaf area index and forest type when estimating photosynthesis in Boreal forest. Remote Sensing of Environment. 43, pp. 303-314.

Bréda NJJ (2003).Ground-based measurements of leaf area index: a review of methods, instruments and current controversies. Journal of Experimental Botany, Vol. 54, No. 392, pp. 2403-2417.

Chen JM, Black TA (1992) Foliage area and architecture of plant canopies from sunfleck size distributions. Agricultural and Forest Meteorology, 60, pp. 249-266.

Chianucci F, Cutini A, Corona P, Puletti N (2014) Estimation of leaf area index in understory deciduous trees using digital photography. Agricultural and Forest Meteorology 198-199, pp. 259-264. 
Clark DB, Olivas, PC, Oberbauer SF, Clark DA, Ryan MG (2008) First direct landscape-scale measurement of tropical rain forest Leaf Area Index, a key driver of global primary productivity. Ecology Letters, 11, pp. 163-172.

Gower ST, Kucharik CJ, Norman JM (1999) Direct and indirect estimation of leaf area index, fAPAR and net primary production of terrestrial ecosystems. Remote Sens. Environ., 70;29-51.

Hall RJ, Davidson DP, Peddle DR (2003) Ground and remote estimation of leaf area index in Rocky Mountain forest stands, Kananaskis, Alberta. Can. J. Remote Sensing, Vol. 29, No. 3, pp. 411-427, 2003.

Jonckheere I, Fleck S, Nackaerts K, Muysa B, Coppin P, Weiss M, Baret $F$ (2004) Review of methods for in situ leaf area index determination Part I. Theories, sensors and hemispherical photography. Agricultural and Forest Meteorology 121: 19-35.

Jose S, Gillespie AR (1997) Leaf area-productivity relationships natural disturbances. Among mixed-species hardwood forest communities of the central hardwood region. Forest Science. 43(1), pp. 56-64.

Kara Ö, Şentürk M, Bolat I, Çakıroğlu K (2011) Kayın, Göknar ve Göknar-Kayın Meşcerelerinde Yaprak Alan İndeksi ile Toprak Özellikleri Arasındaki ilişkiler. Journal of the Faculty of Forestry, Istanbul University, 61 (1), pp. 47-54.

Kucharik CJ, Norman JM, Gower ST (1998) Measurements of branch area and adjusting leaf area index indirect measurements. Agricultural and Forest Meteorology 91: 69-88.

Law BE, Van Tuyl S, Cescatti A, Baldocchi DD (2001) Estimation of leaf area index in open-canopy ponderosa pine forests at different successional stages and management regimes in Oregon. Agricultural and Forest Meteorology 108, pp. 1-14.

Liu Z, Jin G, Qi Y (2012) Estimate of leaf area index in an old-growth mixed broadleaved-Korean pine forest in northeastern China. PLoS ONE 7(3): e32155. doi:10.1371/journal.pone.0032155.

Magurran AE (1988) Ecological Diversity and Its Measurement, Princeton University Press, 179, Princeton, New Jersey.

Magurran AE (2004) Measuring Biological Diversity, Blackwell Publishing Company, Madlen, USA.

Marshall JD, Waring RH (1986) Comparison of methods of estimating leaf-area indexin old-growth Douglas-fir. Ecology, 67(4), pp. 975979.

Mason EG, Diepstratenb M, Pinjuvc GL, Lasserred JP (2012) Comparison of direct and indirect leaf area index measurements of Pinus radiata D. Don. Agricultural and Forest Meteorology 166167, pp. 113- 119.

McAllister DM (2005) Remote Estimation of Leaf Area Index in Forested Ecosystems. University of Calgary, Department of Geomatics Engineering, Master Thesis, 244p.
Nagler PL, Glenn EP, Thompson TL, Huete A (2004) Leaf area index and normalized difference vegetation index as predictors of canopy characteristics and light interception by riparian species on the Lower Colorado River. Agricultural and Forest Meteorology 125, pp. 1-17.

Neves FS, Sperber CF, Campos RI, Soares JP, Ribeiro SP (2013) Contrasting effects of sampling scale on insect herbivores distribution in response to canopy structure. Rev. Biol. Trop. (Int. J. Trop. Biol. ISSN-0034-7744) Vol. 61 (1): 125-137.

Peper PJ, McPherson EG (1998) Comparison of five methods for estimating leaf area index of open-grown deciduous trees. Journal of Arboriculture. 24(2):98-111.

Price JC, Bausch WC (1995) Leaf Area Index Estimation from Visible and Near-Infrared Reflectance Data. Remote Sens. Environ. 52, pp. 5565.

Sampson DA, Allen HL (1995) Direct and indirect estimates of Leaf Area Index (LAI) for lodgepole and loblolly pine stands. Trees 9, pp. 119122.

Song YY, Lu Y, (2015) Decision tree methods: applications for classification and prediction, Shanghai Arch Psychiatry. Apr 25; 27(2), pp. 130-135.

Sumida A, Nakai T, Yamada M, Ono K, Uemura S, Hara T (2009) Ground-based estimation of leaf area index and vertical distribution of leaf area density in a Betula ermanii forest. Silva Fennica 43(5), pp. 799-816.

Turner DP, Acker SA, Means JE, Garman SL (2000) Assessing alternative allometric algorithms for estimating leaf area of Douglas-fir trees and stands. Forest Ecology and Management 126, pp. 61-76.

Yang W, Tan B, Huang D, Rautiainen M, Shabanov NV, Wang Y, Privette JL, Huemmrich KF, Fensholt R, Sandholt I, Weiss M, Ahl DE, Gower ST, Nemani RR, Knyazikhin Y, Myneni RB (2006) MODIS Leaf Area Index Products: From Validation to Algorithm Improvement. leee Transactıons on Geoscience and Remote Sensıng, vol. 44, no. 7, pp. 1885-1899.

Van Pelt R, Sillett SC, Kruse WA, Freund JA, Kramer RD (2016) Emergent crowns and light-use complementarity lead to global maximum biomass and leaf area in Sequoia sempervirens forests. Forest Ecology and Management 375, pp. 279-308.

Waring RH (1983) Estimating forest growth and efficiency in relation to canopy leaf area. Advanced Ecology Research. 13, pp. 327-354.

Watson DJ (1947) Comparative physiological studies in the growth of field crops. I. Variation in net assimilation rate and leaf area between species and varieties, and within and between years. Annals of Botany 11, 41-76. 